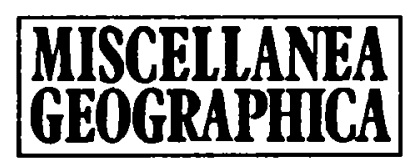

WARSZAWA 1994 Vol. 6

\author{
Urszula Kossowska-Cezak
}

\title{
PERIODS OF PRECIPITATION SHORTAGE IN WARSAW IN THE YEARS 1871-1990
}

The period of drought which occurred in summer of 1992 caused that the research was undertaken on the frequency of occurrence of the periods of such scarce precipitation and conditions of atmospheric circulation which are its cause. An attempt was made to answer these questions on the basis of analysis of monthly precipitation totals in Warsaw from two periods: 1871-1970 at the Astronomical Observatory station in the city centre and within forty years between 1951-1990 at the Okęcie station (the airport in south-west Warsaw).

In order to answer these questions we must find out in the first place what precipitation can be regarded as "scarce," that is what deviation from the norm indicates a considerable precipitation shortage. One should also take into consideration the length of the period of scarce precipitation: even its complete absence during several days is an ordinary phenomenon and does not have to yield hydrographic effects. However, several consecutive months with precipitation constituting even half of its average amount indicate its real shortage. Having considered various methods of determination of "normal" precipitation, i.e. below the norm, as extremely low, the periods of scarce precipitation (called further dry periods) were defined in which months and their sequences have the precipitation total below the average many years' sum by more than 1 standard deviation $(p<\bar{p}-\sigma)$ assuming that:

(1) in the particular months the precipitation total amounts to no more than $25 \%$ of the average sum in this month $(p \leq \bar{p} \cdot 25 \%)$;

(2) in two months' periods the precipitation total constitutes no more than $44 \%$ of the average sum in these months ( $p \leq \bar{p} \cdot 44 \%)$;

(3) in three months' and longer periods the precipitation total does not exceed $50 \%$ of the relevant average sum $(p \leq \bar{p} \cdot 50 \%)$.

If thus defined period of scarce precipitation (dry period) is followed by a subsequent month of average precipitation $(p=\bar{p})$, the precipitation total after this month will not exceed $63 \%$ of the respective average sum regardless of the length of the preceding dry period. This indicates that the ac- 
cepted thresholds of 25,44 and $50 \%$ with reference to one, two and three months' periods correspond to a comparable precipitation shortage.

From the series of monthly precipitation totals in Warsaw in the years 1871-1970 and 1951-1990 all the periods fulfilling the above-mentioned conditions were chosen. The occurrence of two months' and longer sequences which met conditions (2) and (3) has been found out, though not all months in the sequence fulfilled the principal condition. These periods were also taken into account if the precipitation total in the month which failed to meet the initial condition did not exceed $60 \%$ of many years' average. For example, from June to September of 1939 , precipitation totals amounted successively to $45,60,32$ and $59 \%$ of many years' average (49\% throughout the entire period), in July and September precipitation being higher than $p-\sigma$. The latter sequence of months was regarded as a four months' period of scarce precipitation.

In the years 1871-1970 the author has found out twenty-nine dry onemonth periods, thirty two months' periods, ten three months' periods, five four months' periods and one five months' period. Between 1951 and 1990 there were thirteen one-month periods, fourteen two months' periods, two three months' periods and one four months' period (Table 1). Most single dry months occur from September to November, especially in October, but a single dry January was never ascertained. This month occurs most frequently in two months' sequences, following a dry December or preceding a dry February, or in three months' sequences coupled with dry December and February. Generally speaking, two months' dry periods occur most often in winter. The three months' periods usually include July, August and September, while four and five months' periods also occur mostly in summer and autumn (Table 1).

Table 1

Number of periods with scarce precipitation

\begin{tabular}{|c|c|c|c|c|c|c|c|c|c|c|c|c|c|}
\hline $\begin{array}{l}\text { Length of } \\
\text { period (months) }\end{array}$ & I & II & III & IV & V & VI & VII & VIII & IX & $\mathbf{x}$ & XI & XII & $\begin{array}{l}\text { I - } \\
\text { XII }\end{array}$ \\
\hline \multicolumn{14}{|c|}{ Warsaw - Astronomical Observatory, $1871-1970$} \\
\hline 1 & . & 3 & 1 & 1 & 1 & 2 & 2 & 1 & 4 & 9 & 4 & 1 & 29 \\
\hline 2 & 5 & 3 & . & 2 & 1 & 3 & 2 & 2 & 2 & 2 & 3 & 5 & 30 \\
\hline $\mathbf{3}$ & . & . & 2 & 1 & . & 1 & 3 & . & . & 1 & - & . & 10 \\
\hline 4 & 1 & . & . & . & . & 2 & . & 2 & . & . & . & . & $\mathbf{5}$ \\
\hline 5 & . & . & . & . & . & . & . & 1 & . & . & . & . & 1 \\
\hline \multicolumn{14}{|c|}{ Warsaw-Okęcie, 1951-1990 } \\
\hline 1 & . & 2 & . & 3 & . & . & 2 & 1 & . & 4 & . & 1 & 13 \\
\hline 2 & 1 & 2 & 1 & 1 & 1 & . & . & . & 2 & 2 & 1 & 3 & 14 \\
\hline $\mathbf{3}$ & . & . & . & . & . & . & . & . & 1 & . & . & 1 & 2 \\
\hline 4 & . & . & . & . & . & . & . & 1 & . & . & . & . & 1 \\
\hline
\end{tabular}

Remark: Number of 2-month periods and longer ones is put down to the month in which the period starts. 
From the two series under investigation it can be concluded that the probability of occurrence of the single dry months and 2-month periods is similar amounting to 3-4 during 10 years, 3-month and longer to 1 per 10-20 years, including 5-month periods occurring once in a hundred years.

In single dry months the precipitation total is usually lower than 10 $\mathrm{mm}$; it is only in some months within 3-month and longer sequences that the precipitation total exceeds $30 \mathrm{~mm}$. Over the years 1871-1990 three months were found without precipitation: October 1943 (Warsaw, Astronomical Observatory), October 1951 and February 1976 (Warsaw-Okęcie). Monthly totals below $5 \mathrm{~mm}$ (i.e. 1-4 mm) over the century 1871-1970 were recorded 11 times, and over 40 years between 1951 and 19907 times. Among dry 2-month periods the driest were February-March 1982 (totalling $10 \mathrm{~mm}, 20 \%$ of the norm, that is of the respective many years' average sum), as well as December 1881 - January 1882 (totalling $15 \mathrm{~mm}, 22 \%$ of the norm). Among longer periods, a particularly deep deficit occurred within the 3-month sequence from October to December 1920 (totalling 15 $\mathrm{mm}, 13 \%$ of the norm), as well as months of the second half of 1951. The station of the Astronomical Observatory recorded then the only 5-month dry period, from August to December, with the precipitation total of $73 \mathrm{~mm}$ (29\% of the norm), while the Okęcie station recorded a 3-month period, from September to November, with a precipitation total of $20 \mathrm{~mm}(17 \%$ of the norm). In 1951, September and October were particularly dry; a precipitation total at the former station amounted to $5 \mathrm{~mm}$ and at the latter to 1 $\mathrm{mm}$. Among other dry periods one should mention a 4-month sequence from August to November 1959 with a precipitation total of $60 \mathrm{~mm}(33 \%$ of the norm) at the Astronomical Observatory and $62 \mathrm{~mm}$ (36\% of the norm) at Okęcie.

The annual precipitation total in the years which had long-lasting dry periods was usually below the norm, though the magnitude of deviation varied. For example, in 1951 the Astronomical Observatory station recorded $401 \mathrm{~mm}$ ( $71 \%$ of the norm); the same total occurred in 1904 in which there was 1 dry month (March, 13\%) as well as a 4-month period (from June to September, $40 \%)$ and similar $(402 \mathrm{~mm})$ in 1886 which witnessed a 3-month period (from June to September, 34\%). However, the lowest precipitation was recorded in $1942(391 \mathrm{~mm}, 69 \%)$ when there was only 1 dry month (August, $8 \mathrm{~mm}, 11 \%$ ), while the years with 4-month dry periods, i.e. 1885, 1939,1954 , and 1959, had annual precipitation ranging from 85 to $90 \%$ of the norm.

Analysis of the types of atmospheric circulation over Poland (Osuchowska-Klein, 1978, 1991) in dry periods which followed 1900 (there are no calendars of the types of circulation in the previous years) showed characteristic regularities. From November to March in periods of scarce precipitation types of eastern and south-eastern anticyclonic circulation prevailed; the north-eastern and/or central types (high pressure over Poland) were frequent, too. In April and May the type of north-eastern an- 
ticyclonic circulation dominated, but eastern and south-eastern and/or western were frequent, too. From June to September dry periods were marked by a larger share of the types of anticyclonic north-eastern and/or western circulation, the share of the eastern and south-eastern type being fairly high in August and September. In October, scarce precipitation was due to the various types of anticyclonic circulation, both north-eastern and western occurring in summer, and eastern and south-eastern recorded in winter, as well as the central and south-western types which were quite rare. In dry periods the share of the types of anticyclonic circulation characteristic of the given season was at least twice as high as the average and it was accompanied by an increased frequency of anticyclonic types from other directions; their total share sometimes amounts even to $90 \%$ of days of the dry period. Of some importance is also the direction of circulation: in winter months the higher share of the western anticyclonic circulation is typical of rainy and not dry months; the north-eastern cyclonic type, causing heavy rains in summer, is, however, more frequent in dry winter and spring months.

The domination of shares of anticyclonic circulation types in dry months does not mean, however, that each month during which these types prevail is characterized by scarce precipitation. Months were recorded, usually in summer, in which the share of the types of anticyclonic circulation totalled $70 \%$ of days, and the precipitation total considerably exceeded the relevant mean. That was precipitation caused by storms of great intensity and 24hour totals amounting even to $50 \mathrm{~mm}$.

In the light of the criteria adopted it should be said that in 1992 in Warsaw there was a 4-month period of scarce precipitation: from May to August when the precipitation total $(115 \mathrm{~mm})$ constituted $46 \%$ of the norm of that period. This was not an exceptionally dry period; among six 4- and 5-month periods over 120 years (1871-1990), as many as 5 had lower precipitation than in 1992. However, hydrological and economic effects of precipitation shortage in that year were very severe due to two causes. The first was the high air temperature which maintained from June to August (the latter was specially hot). An equally hot month in the period under investigation was recorded only three times (the mean monthly temperature amounting to some $21.5^{\circ} \mathrm{C}$ ) but only one with such a great deviation from the norm (over $4^{\circ} \mathrm{C}$ ). None of the above-mentioned dry periods was as hot as that in 1992 . The second cause of severe effects of scarce precipitation in 1992 was that it occurred in the period of general decrease of amount of precipitation over more than a decade. The last year with precipitation exceeding the norm (about $140 \%$ ) was 1981 . In the subsequent years precipitation totals ranged from $82-102 \%$ of the mean total of the years 1951-1990. Over the decade of 1971-1980 records show 37 months of precipitation totals below $75 \%$ of the norm, while between 1981 and 1990 as many as 48; In the years 1971-1980 in the most rainy month precipitation exceeded $400 \%$ of the norm, and in two others it exceeded $300 \%$, while in the decade of $1981-1990$ in the most rainy month it constituted only $230 \%$ of the relevant many years' average 
total. Thus, the summer drought of 1992 was not only a consequence of the "current" shortage of precipitation, coupled with a high air temperature but also of precipitation shortage which - though being small - maintained almost incessantly.

The character of atmospheric circulation from May to August of 1992 corroborated regularities observed previously: prevalence of anticyclonic types - eastern in May, eastern and western in June, and western in July and August. The share of south-western circulation in August, connected with a well-developed wedge of Azorean high pressure was particularly high (more than $80 \%$ of days). The situation was exceptional because so far scarce precipitation in August usually occurred in the case of prevalence or at least a considerable share of the types of eastern circulations which were inexistent in 1992.

This characterization of frequency and persistence of periods of scarce precipitation, based on the data from one place only (Warsaw) does not enable broader generalizations, especially in relation to the whole country. However, it permits a statement that periodic occurrence of dry months or their sequences is a natural feature of Poland's climate. Their effects may be severe if they are accompanied by a high air temperature and if such a period occurs in the years of general decrease of precipitation.

\section{REFERENCES}

Osuchowska-Klein B., 1978, Katalog typów cyrkulacji atmosferycznej (The Catalogue of Types of Atmospheric Circulation), WKiL, Warszawa.

Osuchowska-Klein B., 1991, Katalog typów cyrkulacji atmosferycznej (The Catalogue of Types of Atmospheric Circulation) (1976-1990), IMGW, Warszawa. 
